ARTÍCULO ORIGINAL

\title{
Actividad antibacteriana in vitro de Ciprofloxacina sobre una cepa autóctona de Escherichia coli: efecto del pH sobre su potencia y efecto de la persistencia bacteriana sobre su modo de acción
}

\author{
Patricelli $\mathrm{P}^{1}$, Dell'Elce $\mathrm{A}^{1}$, Weidmann $\mathrm{C}^{2}$, Ramírez $\mathrm{E}^{1}$, Presa Rossa $\mathrm{C}^{3}$, Aguirre $\mathrm{MS}^{1}$, \\ Cadoche $\mathrm{L}^{2}$, Formentini $\mathrm{E}^{1^{*}}$ \\ ${ }^{1}$ Laboratorio de Farmacología y Toxicología - Facultad de Ciencias Veterinarias - Universidad Nacional del \\ Litoral (FCV-UNL) \\ ${ }^{2}$ Cátedra de Matemática - FCV-UNL \\ ${ }^{3}$ Cátedra de Infectología y Enfermedades Infecciosas - FCV-UNL
}

* Correspondencia: Enrique Formentini, Facultad de Ciencias Veterinarias, Universidad Nacional del Litoral. R.P. Kreder 2805 (3080) Esperanza, Santa Fe, Argentina.

E-mail: eforment@fcv.unl.edu.ar

Recibido: 22 Febrero 2017. Aceptado: 2 Junio 2017. Disponible en línea: 6 Junio 2017

Editor: L. Frizzo

RESUMEN. En este trabajo se evaluó in vitro: (i) el efecto del pH sobre la actividad bactericida de ciprofloxacina (CFX) frente a una cepa autóctona de Escherichia coli y (ii) el efecto de las bacterias persistentes sobre el modo de acción concentración dependiente de CFX. La actividad antibacteriana de CFX disminuyó a causa del descenso del pH, por lo que los valores de concentración inhibitoria mínima (CIM), concentración bactericida mínima (CBM) y concentración de erradicación bacteriana mínima (CEBM) se incrementaron cuando el pH del medio de cultivo descendió de 7,4 a valores de 6,5 y 5,5. La cinética de eliminación bacteriana de CFX fue bifásica a causa de la selección de una sub-población de bacterias persistentes que presentaron una velocidad de eliminación más lenta. Por lo tanto la actividad bactericida de CFX fue definida por su concentración en relación a la CIM y el tiempo durante el cual se mantuvo la exposición de las bacterias a ésta.

SUMMARY. In vitro antibacterial activity of ciprofloxacin against a native strain of Escherichia coli: effect of pH on its potency and effect of bacterial persistence on its mode of action. In this in vitro assay was evaluated: (i) the effect of $\mathrm{pH}$ on the bactericidal activity of ciprofloxacin (CFX) against a native strain of Escherichia coli, (ii) the effect of persister bacteria on the concentration-dependent mode of action of CFX. The antibacterial activity of CFX decreased with reductions of pH, so the values of minimum inhibitory concentration (MIC), minimum bactericidal concentration (MBC) and minimum eradication bacterial concentration (MEBC) were increased when the $\mathrm{pH}$ of the culture medium decreased from 7.4 to 6.5 and 5.5 . The kinetics of bacterial elimination of CFX presented a biphasic pattern because of the selection of a sub-population of persistent bacteria which presented a slower elimination rate. Therefore, the antibacterial activity of CFX was determined by its concentration in reference to MIC values and the time during which the exposure of the bacteria was maintained.

Palabras clave: Escherichia coli, eficacia, modo de acción, $\mathrm{pH}$, bacterias persistentes.

Key words: Escherichia coli, efficacy, mode of action, $\mathrm{pH}$, persister cells.

\section{Introducción}

En el inicio de la era antibiótica, las dosis de los agentes antibacterianos eran las que lograban obtener concentraciones plasmáticas que excedían la concentración inhibitoria mínima (CIM) durante el mayor tiempo posible. En la actualidad, el diseño racional de los regímenes terapéuticos se basa en el conocimiento de las interacciones entre las bacterias, los antibióticos y la respuesta inmune del individuo, utilizando modelos in vitro y modelos animales, a fin de lograr un mejor conocimiento de los aspectos farmacodinámicos (PDs) y farmacocinéticos (PKs) de los antibióticos (Barker et al., 2014).

La potencia y la eficacia de los agentes antimicrobianos son definidas por la CIM y la concentración bac- 
tericida mínima (CBM). La CIM se define como la menor concentración de antibiótico que inhibe el crecimiento visible de bacterias luego de un período de incubación de $24 \mathrm{~h}$ en condiciones preestablecidas. La CBM es la concentración de antibiótico que luego de un período de $24 \mathrm{~h}$ de exposición reduce la población bacteriana inicial en un $99,9 \%$, siendo esta eficacia asociada a la remisión clínica. Un tercer parámetro que también puede considerarse es la concentración de erradicación bacteriana mínima (CEBM), que es la concentración de antibiótico que luego de 24 $\mathrm{h}$ de exposición, reduce el conteo bacteriano inicial en un $99,99 \%$, siendo esta eficacia asociada a la cura bacteriológica (Sidhu et al., 2010).

Los agentes antibacterianos han sido clasificados en base a la correlación entre su eficacia clínica y tres índices farmacocinéticos/farmacodinámicos (PK-PD): (i) la relación entre la máxima concentración plasmática observada de la droga no unida a proteínas o libre $\left(\mathrm{C}_{\max }\right)$ y la $\mathrm{CIM}\left(\mathrm{C}_{\max } / \mathrm{CIM}\right)$, (ii) la relación entre el área bajo la curva de concentración plasmática en función del tiempo de la droga libre $(A B C)$ y la CIM $(A B C / C I M)$ y (iii) el tiempo expresado como \% de un período de $24 \mathrm{~h}$ en el cual la concentración libre de antibiótico es mayor a la CIM ( $\mathrm{t}>\mathrm{CIM}$ ) (Mouton et al., 2005).

La ciprofloxacina (CFX) es un antibiótico sintético que pertenece al grupo de las fluoroquinolonas (FQs), que actúa inhibiendo la ADN-girasa y presenta gran actividad sobre bacterias Gram-negativas y Gram-positivas. Químicamente, es un compuesto anfótero con valores de $\mathrm{pK}_{\mathrm{a}}$ de 8,74 para el grupo carboxílico situado en la posición 3 y de 6,09 para la amina básica terciaria incorporada al anillo piperacilínico situado en la posición 7 (Ross y Riley, 1990). El punto isoeléctrico de CFX es 7,4, eso significa que a este valor de pH los dos grupos químicos se hallan mayoritariamente en su forma no iónica (Torniainen et al., 1996).

Dentro de valores de $\mathrm{pH}$ comprendidos entre 6 y 8 , CFX se halla mayormente en su forma no iónica, activa y liposoluble. Esto último le permite difundir a través de las membranas biológicas e ingresar a los tejidos (Sárközy, 2001). Cuando los valores de pH se alejan de estos límites, su fracción ionizada aumenta y tanto su actividad como su capacidad de difundir a través de las membranas biológicas disminuyen.

El modo de acción de CFX, al igual que el resto de las FQs es concentración-dependiente, es decir que a mayor concentración, mayor será la eficacia antibacteriana (Craig, 1998). Por lo tanto los índices PK-PD de CFX y sus valores predictores de eficacia son: $C_{\max } / C I M(\geq 8$ -12 ) y $A B C / C I M(\geq 100-125)$ (Drusano et al., 2001). No obstante por las características químicas que se mencionaron anteriormente el $\mathrm{pH}$ del medio afecta la eficacia de CFX.

Escherichia coli es un bacilo Gram-negativo, anaerobio facultativo y perteneciente a la familia Enterobac- teriaceae. Esta bacteria coloniza el intestino de los mamíferos pocas horas después de su nacimiento y se le considera un habitante normal del tubo digestivo. Sin embargo hay cepas que pueden ser patógenas y producir diferentes cuadros clínicos, entre ellos, diarrea (Rodríguez-Angeles, 2002). A fin de colonizar el tracto gastrointestinal de los mamíferos, $E$. coli se ha adaptado para sobrevivir y crecer en valores de $\mathrm{pH}$ comprendidos entre 4,5 y 9, (de Jonge et al., 2003). Fuera de estos límites, E. coli reduce significativamente su crecimiento y su sobrevida (Hughes et al., 2007). Dentro de este intervalo de valores de $\mathrm{pH}$, E. coli preserva su actividad enzimática, la estructura de sus proteínas y de su ácido nucleico, manteniendo su pH intra-citoplasmático entre valores de 7,2 a 7,8 (Sloneczewki et al., 1981; Salmond et al., 1984; Zilberstein et al., 1984).

La tolerancia de E. coli a bajos valores de $\mathrm{pH}$, le permite sobrevivir en el tracto gastrointestinal de los mamíferos, donde debe resistir la acidez del medio gástrico antes de alcanzar un ambiente menos ácido en el intestino (Hughes et al., 2007). Teniendo en cuenta estos aspectos debería considerarse cuál sería la verdadera actividad de CFX si ésta actuara sobre bacterias de localización extracelular en tejidos inflamados a causa de una infección bacteriana.

La mayoría de los estudios de actividad de antibióticos sobre una bacteria determinada se realizan in vitro en condiciones estandarizadas y a un valor de $\mathrm{pH}$ cercano a 7,4. Sin embargo, en la periferia de los tejidos inflamados se acumula ácido láctico que hace descender el pH del líquido intersticial en el orden de 0,5 a 1 unidades (Punnia-Moorthy, 1987; de Backer, 2003). Esta acidificación del medio afectaría negativamente la actividad de CFX y el valor de su CIM, que es el principal parámetro PD utilizado como punto de referencia para el diseño de los esquemas posológicos (dosis, frecuencia de administración y duración del tratamiento).

Desde los primeros días de la era antibiótica se ha observado que cuando las bacterias disponen de suficientes recursos para mantener su metabolismo y su crecimiento, los antibióticos no pueden matar a todas las bacterias que se hallen en fase de crecimiento. Luego de un tiempo de exposición, la velocidad de muerte de las bacterias disminuye y una pequeña fracción de la población bacteriana original sobrevive (Bigger, 1944). Esta bacterias se denominan "persistentes" y su resistencia no es génica sino fenotípica (Lewis, 2010). Las bacterias persistentes no crecen o lo hacen lentamente y por esa razón se hacen refractarias a la actividad de los antibióticos, los que necesitan que éstas se hallen en fase de crecimiento logarítmico para ejercer su acción (Levin y Rozen, 2006). Este estado de inactividad metabólica se revierte cuando el antibiótico desaparece y las condiciones ambientales vuelven a ser favorables para su crecimiento (Levin y Rozen, 2006). Por lo tanto, la 
presencia de bacterias persistentes, dentro de una población bacteriana sensible podría afectar el modo de acción y la eficacia de CFX.

El objetivo de este trabajo fue evaluar in vitro: (i) el efecto del $\mathrm{pH}$ sobre la actividad bactericida de CFX frente a una cepa autóctona de E. coli, y (ii) el efecto de las bacterias persistentes sobre el modo de acción concentración-dependiente de CFX.

\section{Materiales y Métodos}

Se utilizó una cepa autóctona de E. coli (E. coli 09-684), aislada de un ternero con signos de gastroenteritis e identificada por múltiplex PCR para factores de virulencia (Franck et al., 1998). El antibiótico utilizado fue un estándar de CFX de pureza conocida (SigmaAldrich $^{\circledR}$, Argentina). Los medios de cultivo utilizados fueron:

(a) caldo Müeller-Hinton (Britania, Argentina), con el que se prepararon tres lotes: (i) con $\mathrm{pH}$ original $(7,3 \pm$ 0,1 ), (ii) con $\mathrm{pH}$ ajustado al valor de 6,5 y (iii) con el $\mathrm{pH}$ ajustado al valor de 5,5. El pH de estos últimos se ajustó con ácido ortofosfórico 0,1 M.

(b) agar Müeller-Hinton (Britania, Argentina).

Inóculos bacterianos - Los inóculos de E. coli 09-684 se prepararon a partir de colonias incubadas durante 24 h sobre placas de agar Müeller-Hinton. Los microorganismos fueron suspendidos en solución isotónica estéril hasta lograr una turbidez equivalente a un valor de 0,5 de la escala de McFarland $\left(1 \times 10^{8}\right.$ unidades formadoras de colonia [UFC]/mL). Posteriormente se realizaron diluciones seriadas hasta obtener una concentración bacteriana final aproximada de $0,5 \times 10^{6}$ $\mathrm{UFC} / \mathrm{mL}$.

Determinación de la CIM de CFX - La CIM de CFX sobre E. coli 09-684 se estimó en caldo Müeller-Hinton con el método de macrodilución en tubo (CLSI, 2008). El valor de $\mathrm{pH}$ final indicado por el fabricante es de 7,3 $\pm 0,1$, por lo que a los fines prácticos de aquí en más se lo nombrará como 7,4. El medio de cultivo se preparó según instrucciones del fabricante y fue esterilizado a $121^{\circ} \mathrm{C}$ durante 15 minutos. Éste fue preparado el día anterior a la realización de los ensayos y hasta el momento de su uso fue almacenado en refrigerador a $7^{\circ} \mathrm{C}$. La CIM de CFX se determinó dentro del intervalo de concentraciones comprendidas entre 0,0039 y 1 $\mu \mathrm{g} / \mathrm{mL}$ en tres grupos de diluciones dobles. El valor de la CIM de CFX fue la menor concentración de antibiótico que inhibió el crecimiento visible de bacterias y fue fijada como el mayor valor observado en los tres grupos de diluciones.

Determinación de la CBM y la CEBM - Luego de determinar la CIM, de los tubos en los que no se observó desarrollo bacteriano visible se tomaron alí- cuotas de $100 \mu \mathrm{L}$ que se extendieron sobre placas de agar Müeller-Hinton, las que se incubaron a $35^{\circ} \mathrm{C}$ durante $24 \mathrm{~h}$, luego de lo cual se procedió al conteo de UFC/placa. Los valores de CBM y CEBM se determinaron como las concentraciones de CFX que lograron una reducción del $99,9 \%$ y $99,99 \%$ del número inicial de bacterias viables respectivamente.

Construcción de curvas de crecimiento bacteriano Los inóculos bacterianos $\left(0,5 \times 10^{6} \mathrm{UFC} / \mathrm{mL}\right)$ en caldo Müeller-Hinton con $\mathrm{pH} 7,4$ y a 6,5 y 5,5 fueron incubados a $35^{\circ} \mathrm{C}$ durante $24 \mathrm{~h}$. De cada uno de ellos se extrajeron alícuotas de $100 \mu \mathrm{L}$ a los siguientes tiempos: $0 ; 1 ; 2 ; 3,5 ; 5 ; 10$ y 24 h. Cada una de esas alícuotas fue diluida en solución fisiológica estéril y $100 \mu \mathrm{L}$ fueron extendidos sobre la superficie de una placa de agar Müeller-Hinton. La dilución proveniente de cada muestra fue sembrada por duplicado y las placas se incubaron en estufa a $35^{\circ} \mathrm{C}$ durante $24 \mathrm{~h}$, luego de lo cual se procedió al conteo de UFC/placa.

Construcción de curvas de muerte bacteriana - Las curvas de muerte se construyeron según la metodología reportada por García Rodríguez et al., (2001). Tres inóculos de aproximadamente 0,5 x $10^{6} \mathrm{UFC} / \mathrm{mL}$ suspendidos en caldo Müeller-Hinton a pH 7,4 y a 6,5 y 5,5 fueron expuestos a concentraciones de CFX equivalentes a 0,25 x CIM, 0,5 x CIM, $1 \times \mathrm{CIM}, 2 \times \mathrm{CIM}$, $4 \times \mathrm{CIM} 8 \times \mathrm{CIM}$ y $32 \times \mathrm{CIM}$, y fueron incubados a $35^{\circ} \mathrm{C}$ durante $24 \mathrm{~h}$. Durante ese período, de cada concentración de antibiótico se extrajeron alícuotas de $100 \mu \mathrm{L}$ a los siguientes tiempos: $0 ; 1 ; 2 ; 3,5 ; 5 ; 10$ y 24 h. Cada alícuota fue diluida en solución fisiológica estéril y 100 $\mu \mathrm{L}$ fueron extendidos sobre la superficie de una placa de agar Müeller-Hinton. Cada dilución fue sembrada por duplicado y las placas se incubaron en estufa a $35^{\circ} \mathrm{C}$ durante $24 \mathrm{~h}$, luego de lo cual se realizó conteo de UFC/placa. El número de UFC/mL de cada tiempo de muestreo en las curvas de crecimiento y muerte bacteriana se determinó multiplicando el número de UFC/placa por un factor derivado de las diluciones de cada muestra. Dado que cada muestra se realizó por duplicado, el número de UFC/mL resultante se expresó como valor promedio. El límite de detección fue de 10 UFC/mL. A fin de facilitar la representación gráfica y la interpretación de las curvas, el conteo bacteriano en cada tiempo de muestro se expresó como $\log _{10}$ $\mathrm{UFC} / \mathrm{mL}$.

Evaluación del efecto del pH sobre el crecimiento de E. coli 09-684 - La integral de UFC/mL en función del tiempo $(A B C)$ se utilizó como estimador de la masa bacteriana desarrollada en las curvas de crecimiento de $E$. coli 09-684 a pH 7,4; 6,5 y 5,5 (Firsov et al., 1997). Los valores de las integrales a $\mathrm{pH} 7,4-6,5$ y 5,5 fueron estimados desde tiempo cero $\left(t_{0}\right)$ hasta las $24 \mathrm{~h}$ $\left(t_{0}-t_{24}\right)$ y se calcularon con el método trapezoidal (Baggot, 2001). Para facilitar el cálculo de las integrales, los valores de UFC/mL de cada tiempo de muestreo fueron expresados como porcentaje del número de $\mathrm{UFC} / \mathrm{mL}$ observadas a $\mathrm{t}_{0}$. 


\section{Criterios de eficacia}

Para evaluar la actividad de las concentraciones de CFX sobre $E$. coli 09-684, se utilizaron criterios de eficacia basados en tres puntos de corte para evaluar la actividad (i) bacteriostática, (ii) bactericida y de (iii) erradicación bacteriana de CFX (Sidhu et al., 2010).

(i) Para la actividad bacteriostática se tomó como referencia el $\log _{10}$ del conteo bacteriano inicial $\left(\log _{10} N_{0}\right)$, y fue definida como la ausencia de eficacia, es decir cuando la diferencia entre el $\log _{10}$ del conteo bacteriano a las $24 \mathrm{~h}\left(\log _{10} \mathrm{~N}_{24}\right)$ y el $\log _{10} \mathrm{~N}_{0}$ fue cero $\left(\log _{10} N_{24}-\log _{10} N_{0}=0\right)$.

(ii) La actividad bactericida fue definida como una reducción igual o mayor a $3 \log _{10}$ respecto del valor de $\log _{10} N_{0}\left(\log _{10} N_{24}-\log _{10} N_{0} \geq-3\right)$. Este valor corresponde a una reducción del $99,9 \%$ del número de bacterias viables inicial y se correlacionaría clínicamente con una reducción de la carga bacteriana suficiente para lograr la remisión del cuadro clínico.

(iii) La actividad de erradicación bacteriana fue definida como una reducción igual o mayor a $4 \log _{10}$ respecto del valor de $\log _{10} N_{0}\left(\log _{10} N_{24}-\log _{10} N_{0} \geq-4\right)$. Este valor corresponde a una reducción del $99,99 \%$ del número de bacterias viables inicial y se correlacionaría clínicamente con una reducción de carga bacteriana suficiente como para permitir la erradicación bacteriana por acción de la respuesta inmune del hospedador, lo que equivaldría a una cura bacteriológica.

Relación entre concentración de CFX y respuesta antibacteriana - La relación entre las concentraciones de CFX y su respuesta antibacteriana se realizó ajustando los valores de $\log _{10} \mathrm{~N}_{24}$ en función de las concentraciones de CFX testeadas con el modelo sigmoideo de respuesta máxima o de Hill, tal como se presenta en la ecuación 1 :

$$
E=E_{0}+\frac{E_{\max } \cdot C^{\alpha}}{C E_{50}^{\alpha}+C^{\alpha}}
$$

Donde $E$ es el efecto observado de una concentración determinada de CFX expresado como la diferencia entre $\log _{10} N_{24}-\log _{10} N_{0}, E_{0}$ es el $\log _{10} N_{0}, E_{\max }$ es el efecto máximo estimado, $C E_{50}$ es la concentración que logra el $50 \%$ de $E_{\max }$ y $\alpha$ es el coeficiente de sigmoidicidad. El ajuste de los datos experimentales se realizó mediante regresión no lineal ponderada de mínimos cuadrados con el software ADAPT II (BMSR, University of Southern California, USA).

Determinación de los valores estimados de CIM, CBM y CEBM - Las concentraciones de CFX necesarias para obtener los siguientes efectos; 0 (bacteriostático 0 CIM), $\quad-3 \quad \log _{10}$ (bactericida 0 CBM) y $\quad-4 \quad \log _{10}$ (erradicación bacteriana o CEMB) se estimaron a partir de los parámetros del modelo sigmoideo de respuesta máxima o de Hill, reordenando la ecuación 1 tal como se presenta a continuación en la ecuación 2 :

$$
C=\left[\frac{\left(E-E_{0}\right) \cdot C E_{50}^{\alpha}}{E_{\max }+E_{0}-E}\right]^{\frac{1}{\alpha}}
$$

Donde $C$ es la concentración de CFX necesaria para obtener un efecto antibacteriano determinado. El resto de los símbolos fueron explicados al pie de la ecuación 1.

Determinación de la fracción no ionizada de CFX a pH 7,4 - 6,5 y 5,5 - La evolución del \% de la fracción ionizada-no ionizada de CFX en función de valores de pH desde 1 a 14 se simuló con la ecuación 3 para el grupo ácido carboxílico $\left(\mathrm{pK}_{\mathrm{a}} 8,74\right)$ :

$$
\% \text { de ácido no ionizado }=\quad 100-\frac{100}{1+10^{\left(p K_{a}-p H\right)}}
$$

y con la ecuación 4 para el grupo básico constituido por la amina básica terciaria $\left(\mathrm{pK}_{\mathrm{a}} 6,09\right)$ :

$\%$ de base no ionizada $=\quad 100-\frac{100}{1+10^{\left(p H-p K_{a}\right)}}$

El valor de la fracción no ionizada de CFX se determinó como la menor fracción no ionizada (sea del grupo carboxílico o de la amina básica terciaria) estimada a cada valor de $\mathrm{pH}$. Posteriormente se examinó si la relación entre las variables (\% de CFX no ionizada y valores estimados de CIM, CBM y CEBM a pH 7,4-6,5 y 5,5 ) podía asimilarse a una ecuación lineal (ecuación de la recta tipo $y=a+b \cdot x$ ), y cuál sería el valor del coeficiente de determinación $\left(r^{2}\right)$ para cada ajuste.

\section{Resultados}

La CIM de CFX a pH 7,4 obtenida por el método de macrodilución (observada) fue de $0,0156 \mu \mathrm{g} / \mathrm{mL}$ (Tabla $3)$, y este valor es el que se tuvo en cuenta para la realización de los ensayos de curvas de muerte bacteriana de $E$. coli 09-684 a pH 7,4 - 6,5 y 5,5.

El pH no afectó el crecimiento de E. coli 09-684. En la Tabla 1, se presentan los valores normalizados de la masa bacteriana desarrollada expresada como ABC. Los valores de $A B C$ estimados a pH 6,5 y 5,5 se expresan como porcentaje del valor de $A B C$ testigo $(\mathrm{pH} \mathrm{7,4).}$

Tabla 1. Valores normalizados de la integral de las unidades formadoras de colonia/mL en función del tiempo (ABC) de $E$. coli 09-684 estimados a partir de los datos experimentales de UFC/mL en función del tiempo obtenidos en las curvas de crecimiento bacteriano. $A B C$ corresponde a la integral de $\mathrm{UFC} / \mathrm{mL}$ en función del tiempo, donde cada conteo bacteriano se expresó como porcentaje del conteo bacteriano inicial. Los valores estimados a pH 6,5 y 5,5 se expresan como porcentaje del valor del $A B C$ testigo estimada a pH 7,4.

\begin{tabular}{ccc}
\hline $\mathrm{pH}$ & $\mathrm{ABC}$ & $\%$ \\
\hline 7,4 & 6629567 & 100,0 \\
6,5 & 9559455 & 144,2 \\
5,5 & 7466577 & 112,6 \\
\hline
\end{tabular}


La inspección visual de las curvas de muerte bacteriana mostró que las concentraciones de CFX disminuyeron su eficacia bactericida a medida que disminuyó el $\mathrm{pH}$ en el medio de cultivo (Figura 1).

Todas las concentraciones iguales o mayores a $1 \times \mathrm{CIM}$ $(\mathrm{pH} 7,4), 4 \times \mathrm{CIM}(\mathrm{pH} 6,5)$ y $32 \times \mathrm{CIM}$ a $(\mathrm{pH} 5,5)$ lograron la erradicación bacteriana tras $24 \mathrm{~h}$ de exposición, pero originaron una cinética de eliminación compuesta por al menos dos fases; la primera caracterizada por una rápida eliminación bacteriana, y la segunda, caracterizada por una eliminación bacteriana lenta (Figura 2).

El ajuste de los datos experimentales de concentración-efecto con el modelo sigmoideo de respuesta máxima o de Hill, mostró que CFX presentó una actividad bactericida de tipo todo o nada $(\alpha>1)$ y una eficacia máxima $\left(E_{\max }\right)$ que fue independiente del $\mathrm{pH}$ del medio de cultivo. Sin embargo, la cinética de eliminación bacteriana mostró que los valores de $C E_{50}$ se incrementaron a medida que descendió el $\mathrm{pH}$ (Figura 3, Tabla 2).

A causa de las diluciones dobles, los valores observados de CIM, CBM y CEBM, fueron muy imprecisos. Por el contrario, el modelo sigmoideo permitió estimar valores más precisos para estos parámetros (Figura 4).

Los valores observados (método de macrodilución) y estimados (modelo sigmoideo) de CIM, CBM y CEBM a valores de $\mathrm{pH}$ 7,4 - 6,5 y 5,5 se presentan en la Tabla 3.

Las curvas de \% de fracción ionizada-no ionizada del grupo carboxílico y amina básica terciaria de CFX en un intervalo de valores de $\mathrm{pH}$ comprendidos entre 1 y 14 se presentan en la Figura 5.

A pH 7,4, el \% de CFX en estado no iónico fue de $95,3 \%$, y de $72,2 \%$ y $20,4 \%$ a valores de $\mathrm{pH} 6,5$ y 5,5 respectivamente. Se observó que el incremento en los valores del \% de CFX en estado no iónico se correspondió con una disminución en los valores estimados de CIM, CBM y CEBM respecto de los valores observados, y que estos valores estimados pudieron ser descriptos por una ecuación lineal. Las gráficas del ajuste de los datos experimentales y los parámetros estimados por regresión lineal simple se presentan en la Figura 6 y la Tabla 4.
Tabla 2. Parámetros farmacodinámicos estimados por el ajuste de los datos experimentales de las curvas concentración-efecto de ciprofloxacina sobre $E$. coli 09-684 observados a valores de $\mathrm{pH} 7,4-6,5$ y 5,5. El ajuste de los datos se realizó mediante regresión no lineal ponderada de mínimos cuadrados con el modelo sigmoideo de respuesta máxima o de Hill. $E_{0}$ es el $\log _{10}$ de $N_{0}, E_{\max }$ es el efecto máximo estimado expresado como diferencia entre $\log _{10} N_{0}$ y $\log _{10}$ de $N_{24}, C E_{50}$ es la concentración que logra el $50 \%$ de $E_{\max }$ y $\alpha$ es el coeficiente de sigmoidicidad que mide la sensibilidad de la respuesta del sistema biológico en estudio.

\begin{tabular}{lccc}
\hline Parámetros & $\mathrm{pH7,4}$ & $\mathrm{pH} \mathrm{6,5}$ & $\mathrm{pH} \mathrm{5,5}$ \\
\hline$E_{0}$ & 3,310 & 2,824 & 3,057 \\
$E_{\max }$ & $-8,374$ & $-8,367$ & $-8,866$ \\
$C E_{50}$ & 0,008 & 0,040 & 0,096 \\
$\alpha$ & 26,068 & 6,666 & 2,774 \\
\hline
\end{tabular}

Tabla 3. Parámetros farmacodinámicos estimados por el ajuste de los datos experimentales de las curvas concentración-efecto de ciprofloxacina sobre $E$. coli 09-684 observados a valores de $\mathrm{pH} 7,4-6,5$ y 5,5. El ajuste de los datos se realizó mediante regresión no lineal ponderada de mínimos cuadrados con el modelo sigmoideo de respuesta máxima o de Hill. (obs) corresponden a los valores obtenidos mediante el método de macrodilución entubo; (est) son valores estimados con el modelo de sigmoideo de respuesta máxima o de Hill.

\begin{tabular}{lcccccc}
\hline \multirow{2}{*}{\begin{tabular}{c} 
Parámetros \\
\multicolumn{1}{c}{$(\mu \mathrm{g} / \mathrm{mL})$}
\end{tabular}} & \multicolumn{2}{c}{$\mathrm{pH} \mathrm{7,4}$} & \multicolumn{2}{c}{$\mathrm{pH} 6,5$} & \multicolumn{2}{c}{$\mathrm{pH} 5,5$} \\
\cline { 2 - 7 } CIM & obs & est & obs & est & obs & est \\
CBM & 0,0156 & 0,0082 & 0,0630 & 0,0357 & 0,1250 & 0,0759 \\
CEBM & 0,0156 & 0,0087 & 0,0630 & 0,0447 & 0,1250 & 0,1262 \\
\hline
\end{tabular}

Tabla 4. Parámetros estimados en el análisis de regresión lineal realizado entre los valores del \% de ciprofloxacina en forma no ionizada y los valores estimados de concentración inhibitoria mínima (CIM), concentración bactericida mínima (CBM) y concentración de erradicación bacteriana mínima (CEBM) E. coli 09-684 a valores de $\mathrm{pH}$ de $7,4-6,5$ y 5,5 estimados con el modelo sigmoideo de respuesta máxima o de Hill. (b) es la pendiente (factor de proporcionalidad entre el \% de CFX no ionizada y las concentraciones efectivas, (a) es el punto de intersección y $(r)$ es el coeficiente de correlación $\mathrm{y}^{2}$ es el coeficiente de determinación.

\begin{tabular}{cccc}
\hline Parámetros & CIM & CBM & CEBM \\
\hline$b$ & $-0,0009$ & $-0,0016$ & $-0,002$ \\
$a$ & 0,0952 & 0,1582 & 0,1957 \\
$r$ & $-0,9943$ & -1 & $-0,9992$ \\
$r^{2}$ & 0,9886 & 1 & 0,9984 \\
\hline
\end{tabular}


A
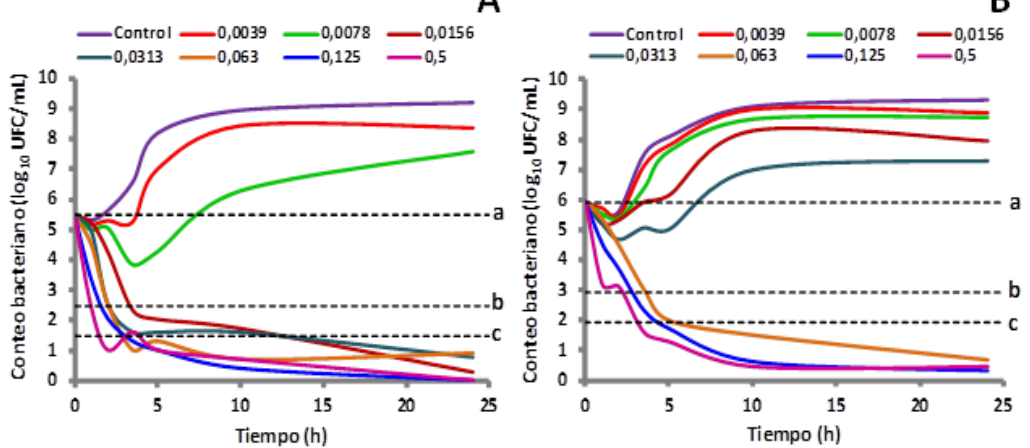

B

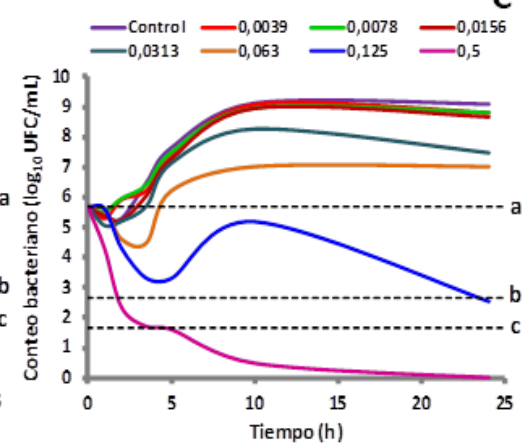

Figura 1. Curvas de muerte bacteriana de $E$. coli $09-684$ realizadas a valores de $\mathrm{pH}$ de A) 7,4, B) 6,5 y C) 5,5. En cada uno de los ensayos la curva control corresponde al desarrollo bacteriano en ausencia de antibiótico. Los valores de las leyendas de cada curva corresponden a la concentración de ciprofloxacina expresada como $\mu \mathrm{g} / \mathrm{mL}$.

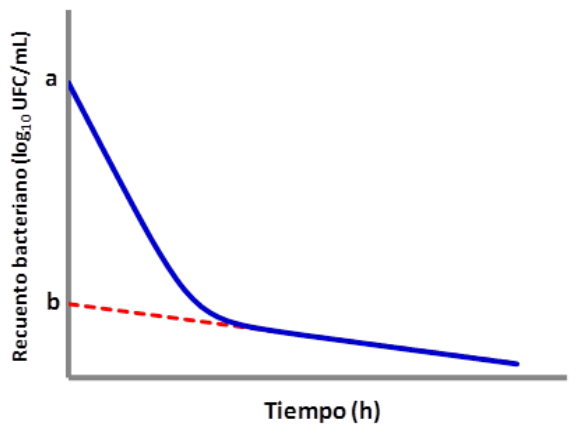

A

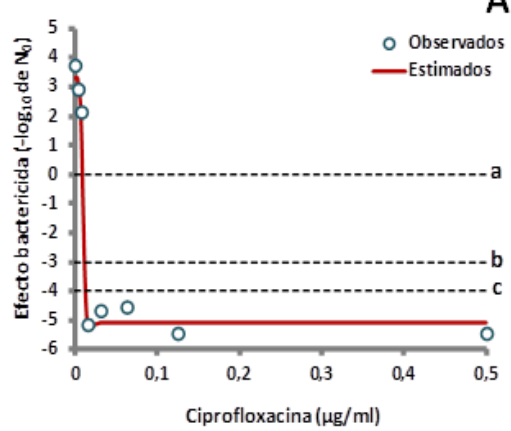

Figura 2. Representación gráfica de la población de E. coli 09-684 que luego de ser expuesta ciprofloxacina presenta una cinética de eliminación bifásica. En las primeras horas de exposición se produce la rápida eliminación de una fracción mayoritaria de bacterias sensibles (a), pero una pequeña fracción de bacterias persistentes (b) sobrevive a la exposición y son eliminadas lentamente.

Figura 3. Curvas concentración-efecto de ciprofloxacina sobre $E$. coli 09-684 a valores de pH de, A) 7,4, B) 6,5 y C) 5,5. La eficacia antibacteriana se halla expresada como la diferencia entre el $\log _{10}$ del conteo bacteriano inicial y el $\log _{10}$ del conteo bacteriano al final del ensayo $(24 \mathrm{~h}$ ). Las gráficas fueron construidas los valores de UFC/mL obtenidos en las curvas de muerte bacteriana, y los valores estimados fueron calculados por ajuste de los datos experimentales con el modelo sigmoideo de respuesta máxima o de Hill. 


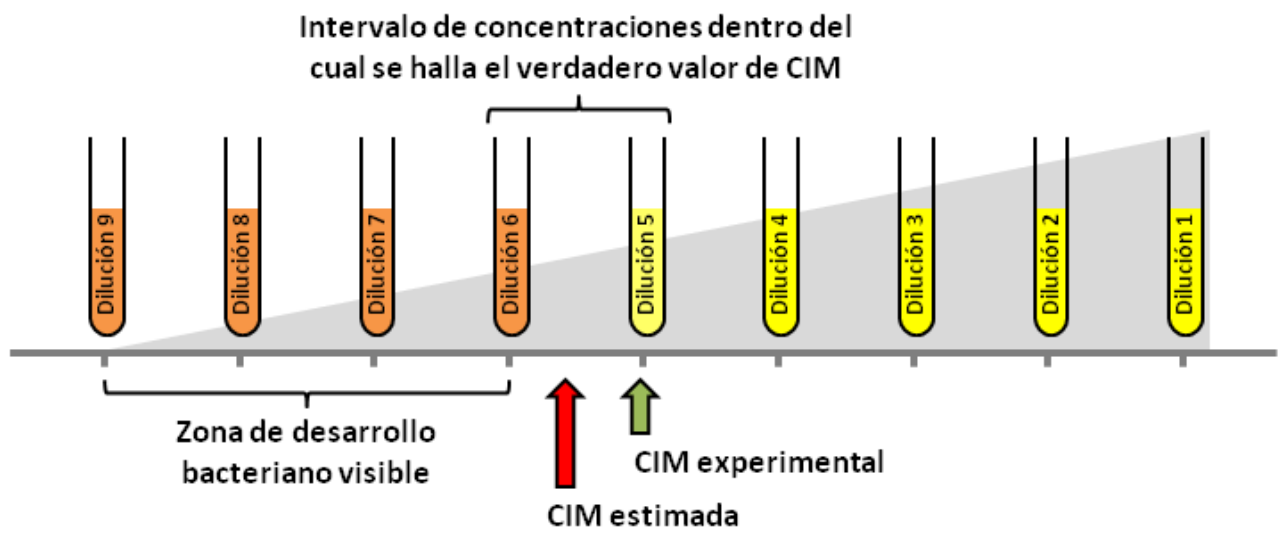

Figura 4. Representación gráfica del método de determinación de la concentración inhibitoria mínima (CIM) mediante el método de dilución. En este, el valor de la CIM es determinado por la concentración de antibiótico presente en la mínima dilución que inhibe el desarrollo bacteriano visible. El área gris muestra como las concentraciones del antibiótico disminuyen a medida que el número de diluciones aumenta. Este método es impreciso ya que no puede determinar el efecto de las concentraciones comprendidas entre el valor de la CIM experimental y la concentración de la dilución siguiente. El método matemático basado en el modelo sigmoideo de respuesta máxima o de Hill permite estimar un valor teórico de CIM dentro de este intervalo de concentraciones.

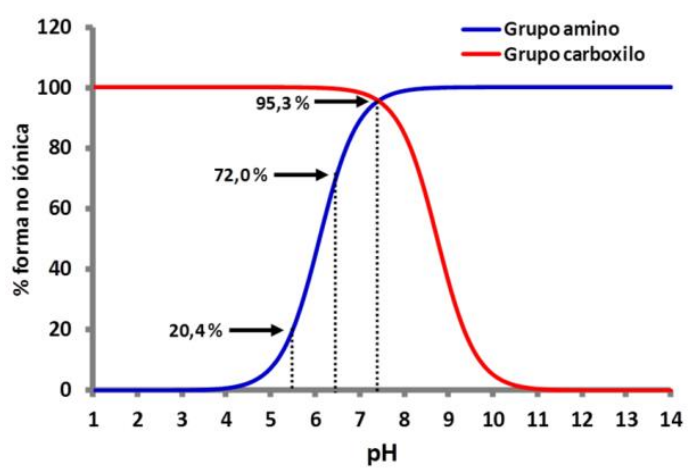

Figura 5. Curvas de \% de fracción ionizada-no ionizada del grupo carboxílico y amina básica terciaria de ciprofloxacina en valores de $\mathrm{pH}$ comprendidos entre 1 y 14.

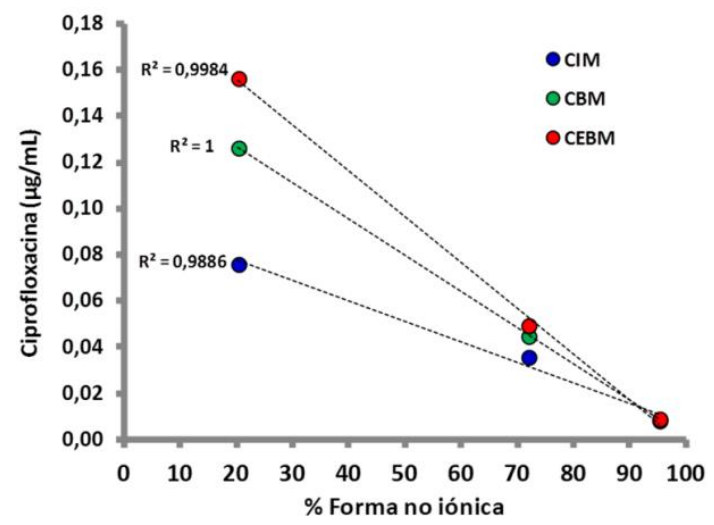

Figura 6. Correlación entre el \% de ciprofloxacina en forma no ionizada a valores de $\mathrm{pH}$ de $7,4(\bullet)-6,5(\bullet)$ y $5,5(\bullet)$ y los valores de concentración inhibitoria mínima (CIM), concentración bactericida mínima (CBM) y concentración de erradicación bacteriana mínima (CEBM) sobre E. coli 09-684 estimados por el modelo sigmoideo de respuesta máxima o de Hill.

\section{Discusión}

Los resultados obtenidos en este trabajo arrojan luz sobre cuatro aspectos de la farmacodinamia de CFX sobre E. coli 09-684: i) la eficacia de CFX, (ii) el modo de acción de CFX, iii) el efecto del pH sobre su actividad antibacteriana y iiii) la estimación de los parámetros farmacodinámicos utilizados para evaluar su actividad antibacteriana.

\section{Modo de acción de CFX sobre E. coli 09-684}

El modo de acción de CFX sobre E. coli 09-684 se evaluó tomando como referencia la actividad farmacodinámica observada a un $\mathrm{pH}$ de 7,4. En este estudio se observó que concentraciones iguales o mayores a la $\operatorname{CIM}(0,0156 \mu \mathrm{g} / \mathrm{mL})$ lograron reducir el conteo bacteriano de $E$. coli $09-684$ a niveles equivalentes a la erradicación bacteriana. Similares resultados fueron reportados para varios antibióticos del grupo de las FQs que actuando sobre otras bacterias, alcanzaron la máxima eficacia con concentraciones que no fueron mayores a $4 \times \mathrm{CIM}$ (Haritova $\mathrm{y}$ Russenova, 2010; Cengiz et al., 2013; Filocamo et al., 2011; Ferran et al., 2013).

La relación concentración-eficacia de CFX sobre $E$. coli 09-684 fue de tipo todo o nada $(\alpha>1)$, es decir que el incremento en la concentración desde $0,0078 \mu \mathrm{g} / \mathrm{mL}$ a $0,0156 \mu \mathrm{g} / \mathrm{mL}$ determinó que su actividad pasara de una mera reducción del desarrollo bacteriano a una reducción del conteo de bacterias viables equivalente a la erradicación bacteriana (Figura $1 \mathrm{~A}$ ).

La actividad concentración-dependiente de CFX se observó durante las primeras $5 \mathrm{~h}$ de exposición para todas las concentraciones $\geq 1 \times \mathrm{CIM}$, las que lograron la 
rápida eliminación de una gran fracción del conteo bacteriano inicial y alcanzaron una eficacia compatible con una erradicación bacteriana teórica. Sin embargo, las bacterias sobrevivientes se eliminaron en forma lenta y muchas permanecieron viables hasta luego de $24 \mathrm{~h}$ de exposición al antibiótico.

La lenta eliminación de esta sub-población de bacterias persistentes puede ser explicada porque la actividad de CFX se redujo a causa de la disminuida respiración celular (Lobritz et al., 2015) y la mayor actividad de las bombas de eflujo de este tipo de bacterias ( $\mathrm{Pu}$ et al., 2016). La presencia de una subpoblación de bacterias persistentes determinó que la erradicación de E. coli 09-684 pasara a depender del tiempo de exposición a CFX. Estos hallazgos nos llevan a cuestionarnos si CFX debe seguir siendo considerado un antibiótico con actividad "concentración dependiente" o si por el contrario, el éxito terapéutico sería también consecuencia de la duración del tiempo de exposición.

Este planteo fue evaluado por Blot et al., (2014), quienes ubicaron a las FQs en un nivel intermedio entre los antibióticos con actividad tiempo-dependiente y los antibióticos concentración-dependiente, proponiendo la denominación de antibióticos con actividad concentración-dependiente con tiempo-dependencia.

\section{Efecto del pH sobre la actividad antibacteriana de CFX}

Igualmente a lo reportado por Endorgan-Yildrin et al. (2011), la acidificación del medio de cultivo no modificó el crecimiento de E. coli 09-684. Este hallazgo permite inferir que la reducción de la actividad antibacteriana de CFX solo puede ser atribuida al descenso del $\mathrm{pH}$ y no a un lento metabolismo con disminución de su velocidad de desarrollo.

En las curvas de muerte bacteriana realizadas a $\mathrm{pH} 7,4$ se observó la máxima actividad antibacteriana para todas las concentraciones de CFX $\geq$ a $0,0156 \mu \mathrm{g} / \mathrm{mL}$, ya que a este $\mathrm{pH}$ la molécula se halla en su punto isoeléctrico, mayoritariamente en su forma no ionizada $(95,3 \%)$, la cual es también su forma farmacológicamente activa (Figura 5).

El descenso de los valores de $\mathrm{pH}$ incrementó la ionización de la amina básica terciaria y disminuyó la actividad antibacteriana de CFX, lo que tuvo como consecuencia un incremento en los valores de CIM, CBM y CEBM a pH 6,5 y 5,5 respectivamente.

Los parámetros obtenidos tras el ajuste de las curvas de relación concentración-efecto (Tabla 2), muestran que el descenso del $\mathrm{pH}$ del medio de cultivo disminuyó la potencia de $C F X$, ya que los valores de $C E_{50}$ se incrementaron 5 y 12 veces al descender el $\mathrm{pH}$ a valores de 6,5 y 5,5 respectivamente. Estos resultados son concordantes con los reportados por EndorganYildrin et al. (2011) quienes observaron que los valores de CIM de levofloxacina sobre E. coli ATCC 25922 y Klebsiella oxytoca en orina se incrementaron al acidificar el pH de ésta.

Sin embargo la acidificación del $\mathrm{pH}$ del medio de cultivo no afectó la eficacia antibacteriana de CFX, ya que los valores estimados de $E_{\max }$ fueron similares en los tres valores de $\mathrm{pH}$, y en todos los casos éstos se lograron con elevadas concentraciones de CFX.

La implicancia clínica de estos hallazgos radica en que, en caso de una infección bacteriana, el pH de los fluidos extracelulares puede descender respecto de su valor fisiológico de 7,4. De esta manera un descenso del $\mathrm{pH}$ del líquido intersticial de 7,4 a 6,5 no afectaría la supervivencia ni el crecimiento de $E$. coli, pero si incrementaría la fracción ionizada de CFX, reduciendo su actividad al punto que los valores observados de CIM, CBM y CEBM ascenderían de $0,0156 \mu \mathrm{g} / \mathrm{mL}$ a $0,0630 \mu \mathrm{g} / \mathrm{mL}$ (Tabla 3).

Históricamente, la CIM ha sido el principal parámetro PD utilizado para el diseño de los regímenes terapéuticos. No obstante, la CIM que se utiliza para calcular los índices de eficacia antibacteriana $\left(C_{\max } / C I M\right.$, $\mathrm{ABC} / \mathrm{CIM}$ y $\mathrm{t}>\mathrm{CIM}$ ) es la que se estima mediante condiciones estandarizadas y con un valor de $\mathrm{pH}$ fijado en 7,4. Considerando que un $\mathrm{pH}$ de 7,4 no refleja el $\mathrm{pH}$ del líquido intersticial en los tejidos inflamados, la modificación del pH del medio de cultivo de 7,4 a 6,5, simularía de manera más fidedigna una condición de acidificación del líquido intersticial en caso de un proceso inflamatorio debido a una infección bacteriana. En vista de lo expuesto, la inquietud que surge es si en el cálculo de las dosis de CFX se debería reemplazar el valor de la CIM estimada por métodos estandarizados por el valor de la CIM estimada modificando el $\mathrm{pH}$ del medio de cultivo a un valor de 6,5 .

\section{Estimación de los parámetros farmacodinámicos de CFX}

Los valores observados de CIM, CBM y CEBM se estimaron mediante técnicas basadas en el principio de dilución, realizadas utilizando diluciones 1:2 de soluciones de CFX, lo que presenta una imprecisión del $100 \%$, ya que los verdaderos valores de éstos se encontrarán entre estos valores observados y las concentraciones inferiores presentes en las diluciones siguientes (García Rodríguez et al., 2001). Considerando esta limitación, Forrest et al. (1997), introdujeron el concepto de CIM punto medio (MIC mid-point), que es un valor de concentración promedio entre el valor observado de la CIM y el siguiente valor menor en la serie de diluciones. Para salvar estas imprecisiones de estimación, algunos autores proponen utilizar varias series de diluciones dobles superpuestas (Sidhu et al., 2010), Sin embargo este procedimiento tiene las desventajas de ser muy laborioso, y aunque reduce el error de estimación no lo elimina. 
En la actualidad, se dispone de paquetes informáticos que permiten utilizar modelos matemáticos para estimar de manera más precisa los valores de CIM, CBM y CEBM. En este estudio estos valores se estimaron por ajuste de los datos experimentales de concentración-efecto utilizando el modelo sigmoideo de respuesta máxima o de Hill. A partir de los parámetros estimados (Tabla 2) y despejando la ecuación 1 , se obtuvo la ecuación 2 que permitió estimar numéricamente los valores aproximados de CIM, CBM y CEBM (Tabla 3). Los parámetros estimados presentan valores intermedios entre los intervalos comprendidos entre los valores observados y que corresponden a la dilución siguiente. Una representación esquemática referida a la estimación de la CIM mediante el método de dilución (valores observados) y los obtenidos mediante el modelo de Hill (valores estimados) se presenta en la Figura 4.

Debido a que la relación concentración-efecto de CFX sobre $E$. coli 09-684 fue del tipo todo o nada, no se observaron diferencias entre los valores observados de CIM, CBM y CEBM obtenidos por el método de dilución a valores de $\mathrm{pH}$ de 7,4 y 6,5 (Tabla 3). Sin embargo los valores estimados con el modelo de Hill, presentaron diferencias con respecto a los valores observados llegando a ser en algunos casos un $50 \%$ menores.

En base a los resultados obtenidos y aceptando que en los tejidos el $\mathrm{pH}$ en el sitio de infección tiende a la acidez, es de esperar que la actividad de CFX disminuya en función de la reducción de su forma no iónica. El ensayo in vitro mostró que en presencia de $\mathrm{pH} 6,5$ la CIM observada de CFX fue de $0,063 \mu \mathrm{g} / \mathrm{mL}$, sin embargo el modelo de Hill estimó un valor de 0,0357 $\mu \mathrm{g} / \mathrm{mL}$, lo que significa una reducción del valor observado en un $43,3 \%$

Estudios clínicos realizados en medicina humana demuestran que para CFX actuando sobre bacterias gram-negativas, la probabilidad de una remisión clínica asciende por encima del $80 \%$, cuando la dosis de CFX permite obtener un valor de $A B C / C I M \geq 125$, mientras que la cura bacteriológica producida por la erradicación del agente causal se ha relacionado con valores de $A B C / C I M$ entre 125 y 250 (Forrest et al., 1993).

Si se considera que el valor del $A B C$ es directamente proporcional al valor de la dosis (D) e inversamente proporcional al aclaramiento corporal (CL), el cual es constante para cada antibiótico y para cada especie animal $(A B C=D / C L)$, se deduce que para incrementar el valor del índice $A B C / C I M$, sería necesario incrementar el valor de la dosis (Toutain and BousquetMélou, 2004).

Si analizamos estos resultados desde el punto de vista clínico, los valores estimados por el modelo de Hill pueden resultar más razonables para el diseño de esquemas de dosificación, a fin de evitar dosis excesivamente elevadas de CFX.

\section{Conclusiones}

Los resultados obtenidos en este trabajo muestran que el modo de acción de CFX sobre E. coli 09-684, fue diferente según ésta actuase sobre una población mayoritariamente sensible a que si actuase sobre una sub-población de bacterias persistentes. Este fenómeno se explica porque la población bacteriana expuesta a CFX fue fenotípicamente heterogénea, donde la mayoría de las bacterias fueron sensibles a la actividad de ésta, y una pequeña fracción de bacterias persistentes detuvo su actividad metabólica y su crecimiento haciéndose transitoriamente refractarias a su actividad. Por lo tanto la actividad bactericida de CFX dependió tanto de la concentración de ésta en relación a la CIM como del tiempo durante el cual se mantuvo la exposición.

Con respecto al efecto del $\mathrm{pH}$ sobre la farmacodinamia de CFX sobre $E$. coli 09-684, éste tiene dos aspectos importantes, ya que el descenso del mismo no afecta el metabolismo ni el desarrollo de $E$. coli 09-684, pero si reduce la actividad de CFX por incremento de la fracción ionizada de la molécula. Esto debería ser tenido en cuenta en el diseño de los regímenes posológicos, ya que los valores de $\mathrm{CIM}$ obtenidos a $\mathrm{pH} 6,5$, serían mucho más confiables a la hora de calcular las dosis de CFX, considerando que este $\mathrm{pH}$ se halla en la periferia de los tejidos inflamados.

En este sentido, los valores de CIM estimados por el modelo de Hill son más precisos que los obtenidos por el método de dilución, y contribuirían a que no se estimaran dosis excesivamente elevadas para este tipo de antibióticos.

\section{Agradecimientos}

Este estudio pudo realizarse gracias al soporte económico proporcionado por la Universidad Nacional del Litoral, Argentina, en el marco de la convocatoria de proyectos CAI+D 2011. Los autores también agradecen a la Lic. Analía Romero Scharpen del Laboratorio de Análisis de Alimentos (LAA), ICIVET Litoral ConicetUNL, por habernos proporcionado valiosa información para la realización de este trabajo.

\section{Bibliografía}

Baggot JD. 2001. The physiological basis of veterinary clinical pharmacology. Ed. Blackwell Science, London. 283 pp.

Barker CIS, Germovsek E, Hoare RL, Lestner JM, Lewis, Standingb JF. 2014. Pharmacokinetic/pharmacodynamic modelling approaches in paediatric infectious diseases and immunology. Adv. Drug Deliv. Rev. 73: 127-139. 
Bigger WB. 1944. Treatment of Staphylococcal infections with Decixillin. Lancet. 244: 497-500.

Blot SI, Pea F, Lipman J. 2014. The effect of pathophysiology on pharmacokinetics in the critically ill patient--concepts appraised by the example of antimicrobial agents. Adv. Drug Deliv. Rev. 77: 3-11.

Cengiz M, Arslan E, Sorucu A. 2013. In vitro pharmacodynamics of enrofloxacin against Escherichia coli gyrA Mutant. J. Anim. Vet. Adv. 10: 2384-2388.

CLSI (Clinical and Laboratory Standards Institute). 2008. Development of in vitro susceptibility testing criteria and quality control parameters for veterinary antimicrobial agents; Approved guideline. 3rd Edition, Document M37-A3, Volume 28, Number 7. Wayne, Pennsylvania USA.

Craig WA. 1998. Pharmacokinetic/pharmacodinamic parameters: rationale for antibacterial dosing of mice and men. Clin. Infect. Dis. 26: 1-12

de Backer D. 2003. Lactic acidosis. Minerva Anestesiol. 69: 281-284.

de Jonge R, Takumi K, Ritmeester WS, van Leusden FM. 2003. The adaptive response of Escherichia coli 0157 in an environment with changing $\mathrm{pH}$. J. Appl. Microbiol. 94: 555560

Drusano GL, Preston SL, Hardalo C, Hare R, Banfield C, et al. 2001. Use of preclinical data for selection of a phase II/III dose for evernimicin and identification of a preclinical MIC breakpoint. Antimicrob. Agents Chemother. 45:13-22.

Endorgan-Yildrin Z, Burian A, Manafi M, Zeitlinger M. 2011. Impact of $\mathrm{pH}$ on bacterial growth and activity of recent fluoroquinolones in pooled urine. Res. Microbiol. 162: 249252.

Ferran AA, Bibbal D, Pellet T, Laurentie M, et al. 2013. Pharmacokinetic/pharmacodynamic assessment of the effects of parenteral administration of a fluoroquinolone on the intestinal microbiota: comparison of bactericidal activity at the gut versus the systemic level in a pig model. Int. J. Antimicrob. Agents. 42, 429-435.

Filocamo A, Bisignano C, D'arrigo M, Ginestra G, Mandalari G, Galati EM. 2011. Norfloxacin and ursolic acid: in vitro association and postantibiotic effect against Staphylococcus aureus. Lett. Appl. Microbiol. 53: 193-197.

Forrest A, Nix DE, Ballow $\mathrm{CH}$, Goss TF, Birmingham MC, Schentag JJ. 1993. Pharmacodynamics of intravenous ciprofloxacin in seriously ill patients. Antimicrob. Agents. Chemother. 37: 1073-1081.

Forrest A, Chodosh S, Amantea MA, Collins DA, Schentag JJ. 1997. Pharmacokinetics and pharmacodynamics of oral grepafloxacin in patients with acute bacterial exacerbations of chronic bronchitis. J. Antimicrob. Chemother. 40 Suppl A: 45-57.

Franck SM, Bosworth BT, Moon HW. 1998. Multiplex PCR for enterotoxigenic, attaching and effacing, and Shiga toxinproducing Escherichia coli strains from calves. J. Clin. Microbiol. 36: 1795-1797.

García Rodríguez J, Cantón R, García Sánchez J, Gómez-Lus M, Martínez Martínez L, Rodríguez-Avial C, Vila J. 2001. Métodos Especiales para el Estudio de la sensibilidad a los Antimicrobianos. En Juan J. Picazo Editor: Procedimientos en Microbiología Clínica; SEIMC Sociedad Española de
Enfermedades Infecciosas y Microbiología Clínica. Primera Edición. España. pp 1-38.

Haritova AM, Russenova NV. 2010. In vitro antibacterial effect of enrofloxacin determined by the time-killing curves analysis. Bulg. J. Vet. Med. 13: 218-226.

Hughes BS, Cullum AJ, Bennett AF. 2007. Evolutionary adaptation to environmental $\mathrm{pH}$ in experimental lineages of Escherichia coli. Evolution. 61:1725-1734.

Levin BR, Rozen DE. 2006. Non-inherited antibiotic resistance. Nat. Rev. Microbiol. 4: 556-562.

Lewis K. 2010. Persister cells and the paradox of chronic infections. Microbe. 5: 429-437.

Lobritz MA, Belenky $\mathrm{P}$, Porter $\mathrm{CB}$, Gutierrez A, Yang JH, Schwarz EG, Dwyer DJ, Khalil AS, Collins JJ. 2015. Antibiotic efficacy is linked to bacterial cellular respiration. Proc. Nat. Acad. Sci. USA. 112: 8173-8180.

Mouton JW, Dudley MN, Cars O, Derendorf H, Drusano GL. 2005. Standardization of pharmacokinetic/pharmacodynamic (PK/PD) terminology for anti-infective drugs: an update. J. Antimicrob. Chemother. 55: 601-607.

Pu Y, Zhao Z, Li Y, Zou J, Ma Q, Zhao Y, Ke Y, Zhu Y, Chen H, Baker Ma, Ge H, Sun Y, Xie Xs, Bai F. 2016. Enhanced efflux activity facilitates drug tolerance in dormant bacterial cells. Mol. Cell. 62: 284-294.

Punnia-Moorthy A. 1987. Evaluation of $\mathrm{pH}$ changes in inflammation of the subcutaneous air pouch lining in the rat, induced by carrageenan, dextran and Staphylococcus aureus. J. Oral Pathol.16: 36-44.

Rodríguez-Angeles G. 2002. Principales características y diagnóstico de los grupos patógenos de Escherichia coli. Salud pública Mex. 44: 464-475.

Ross DL, Riley CM. 1990. Aqueus solubilities of some variously substituted quinolone antimicrobials. Int. J. Pharmaceut. 63: 237-250.

Salmond CV, Kroll RG, Booth IR. 1984. The effect of food preservatives on $\mathrm{pH}$ homeostasis in Escherichia coli. J. Gen. Microbiol. 130: 2845-2850.

Sárközy G. 2001. Quinolones: a class of antibacterial agents. Vet. Med. - Czech. 46(9-10): 257-274.

Sidhu PK, Landoni MF, Aliabadi FS, Lees P. 2010. PK-PD integration and modeling of marbofloxacin in sheep. Res. Vet. Sci. 88: 134-141.

Slonczewski JL, Rosen BP, Alger JR, Macnab RM. 1981. pH homeostasis in Escherichia coli: measurement by 31P nuclear magnetic resonance of methylphosphonate and phosphate. Proc. Natl. Acad. Sci. USA. 78: 6271-6275.

Torniainen K, Tammilehto S, Ulvi V. 1996. The effect of $\mathrm{pH}$, buffer type and drug concentration on photodegradation of ciprofloxacin. Int. J. Pharmaceut. 132: 53-61.

Toutain PL, Bousquet-Mélou A. 2004. Bioavailability and its assessment. J. Vet. Pharmacol. Ther. 27: 455-466.

Zilberstein D, Agmon V, Schuldiner S, Padan E. 1984. Escherichia coli intracellular $\mathrm{pH}$, membrane potential, and cell growth. J. Bacteriol. 158: 246-252. 